\title{
Editorial
}

\section{Sesquicentenario de la Fundación de la Facultad de Medicina}

Es una satisfacción muy especial dirigirme a Usted, estimado lector, en el año en que, jubilosos, conmemoramos el Sesquicentenario de la Fundación de la Facultad de Medicina de San Fernando, alma máter de la medicina nacional y pilar fundamental de la Universidad Decana de América.

La Universidad, la más antigua, apreciada y universal de las instituciones, encargada de crear y trasmitir ciencia y conocimiento, cultiva a su vez, los más preciados valores del espíritu. Como todo organismo vivo, se desarrolla y evoluciona, trasciende y se proyecta mas allá de sus límites y del tiempo, en función de la calidad, pertinencia y mérito de su obra.

Si bien, la primera Cátedra de Medicina en San Marcos se crea en 1576, a 25 años de su fundación, el desarrollo durante la colonia avanza lentamente, formándose las Cátedras de Método Galénico o de Arte Curativo a finales de 1691, Anatomía en 1711 y, por gestión de Unanue, el Anfiteatro Anatómico, en 1792.

Los estudios clásicos y doctrinarios que impartía por tres años la universidad, debían complementarse por igual período de tiempo, con el ejercicio práctico y desarrollo clínico, en el manejo de enfermos, que cumplían los alumnos en los hospitales mayores de Lima, formándose así las llamadas "Escuelas Prácticas de Medicina y Cirugía”. Centros de práctica obligada y requisito indispensable para rendir examen y aspirar a la titulación.

Es en esta época que emerge la egregia figura del sabio Hipólito Unanue, tratando de perfeccionar la enseñanza médica, dando una formación integral y uniforme a médicos y cirujanos. Establece sus 'Conferencias Clínicas' y propone al Virrey Fernando de Abascal la creación del Colegio de Medicina y Cirugía de San Fernando, el que se inaugura en 1811, en la esquina de las calles de San Andrés y Sacramento de Santa Ana, frente a la plaza del mismo nombre (hoy Plaza Italia), cumpliéndose la gran aspiración de Unanue.

San Fernando siempre fue destacado actor en la vida nacional, especialmente en la etapa de transición que puso fin a la Colonia y dio inicio a la República; en ella, sus profesores y alumnos, dirigidos por Unanue, contribuyeron a fijar las bases de la nacionalidad, mérito por el cual el 27 de agosto de 1821, el Protector del Perú Don José de San Martín, cambió su denominación por la de Colegio de la Independencia. Este nombre lo conservó hasta el 9 de setiembre de 1856, cuando el Presidente Constitucional D. Ramón Castilla aprueba el Reglamento de Funcionamiento y crea la Facultad de Medicina de San Fernando, pilar fundamental de nuestra Universidad, cuyo Sesquicentenario estamos conmemorando.

Unanue tuvo el mérito notable de haber forjado desde sus inicios la Escuela Médica Peruana, hasta convertirla en Facultad, con la atribución no solo de impartir la enseñanza, sino -lo que es igualmente trascendente- el emitir los grados y títulos correspondientes. Por ello, es con justicia reconocido como "Padre de la Medicina Nacional".

Cayetano Heredia, fue otro gran sanfernandino, tres veces Rector del Colegio de la Independencia y Primer Decano de San Fernando. Fue autor del primer Reglamento Orgánico de la Facultad, su obra maestra, y verdadero artífice de la evolución favorable de la enseñanza de la Medicina en el 
Perú, en el casi cuarto de siglo que le correspondió dirigirla. A ello se suma el trato humano y paternal a sus docentes y alumnos. El impulso a la docencia y las medidas de salubridad que impartió en beneficio de la comunidad, le han tornado paradigmático y le permiten compartir con Unanue el sitial de honor que San Fernando reserva para sus hijos más ilustres.

Como hito notable y trascendente en la historia de nuestra Facultad, el 5 de octubre de 1885, muere en la Maison de Santé, Daniel Alcides Carrión, alumno sanfernandino, mártir de la medicina, quien se inmoló por sus semejantes al inocularse el líquido de un verrucoma. Con ello trataba de demostrar unidad clínica entre la llamada 'Fiebre de La Oroya' y la verruga, que en ese entonces diezmaba la población de las quebradas andinas. Carrión completó, con la nobleza de su gesto, la trilogía magnífica que con Unanue y Heredia constituyen las figuras paradigmáticas de nuestra medicina. El martirologio de Carrión es recordado en su memoria como "Día de la Medicina Nacional".

Se ha dicho que San Marcos es el Perú, y como Universidad, la más antigua y emblemática, por muchos años la única. Su devenir ha estado siempre ligado estrechamente a los acontecimientos políticos que hicieron la historia del Perú. Así, cuando en 1960, siendo Presidente D. Manuel Prado Ugarteche, Rector Luis Alberto Sánchez y Decano Alberto Hurtado Abadía, se establece el nuevo Estatuto Universitario que implanta el Tercio Estudiantil en el Consejo de Facultad, lo cual no es aceptado por el Decano y la mayoría de los profesores, por considerarlo «incompatible con los requisitos que exige la educación médica y desvirtuarse la función que corresponde a los alumnos en la vida universitaria». Por tal razón, el 11 de agosto de 1961, las autoridades y más de 400 profesores renuncian masivamente a San Fernando en dramática protesta y formaron, posteriormente, lo que es hoy la Universidad Peruana Cayetano Heredia. Cisma traumático que interrumpió el largo camino que inició Hipólito Unanue, fortaleció Cayetano Heredia y engrandecieron una pléyade de sabios maestros sanfernandinos que elevaron a las más altas cumbres la medicina nacional.

Quienes tuvimos el infortunio y a su vez privilegio de vivir esos aciagos momentos, fuimos testigos de excepción del esfuerzo denodado de maestros, como Héctor Colichón Arbulú, Alberto Cuba Caparó y Alberto Guzmán Barrón, entre otros ilustres profesores, que no abandonaron San Fernando, para reestructurar nuestra gloriosa casa de estudios y encaminarla por una senda cada vez más difícil, de creciente complejidad y desigual competencia. Cuando dejamos de ser la única Facultad de Medicina del país, época en que todos éramos sanfernandinos, pasamos a ser la simiente, de la que se han forjado la mayoría de las 28 facultades de medicina que existen actualmente en el país.

Es ésta, la historia de la Medicina Peruana, resumida en la historia de San Fernando, la que conmemoramos en este Sesquicentenario, en que cicatrizadas las heridas del doloroso trauma del 61 y comprendiendo la posición principista de nuestros maestros de entonces, mas no compartiendo su actitud, hemos dejado atrás el pasado, hemos aprendido de nuestros errores, fortaleciéndonos en el trabajo conjunto y armonioso, sumando esfuerzos en metas comunes, dejando posiciones personales o de grupo y pensando solo en la excelencia académica y administrativa de nuestra Facultad, con la esperanza de una competencia interinstitucional justa y alturada, como corresponde a los herederos de tan ilustre y noble estirpe.

Dr. A. Ulises Núñez Chávez

Decano de la Facultad de Medicina

Universidad Nacional Mayor de San Marcos 